\title{
Adsorption of ammonia using mesoporous alumina prepared by a templating method
}

\author{
Changjoo Yeom, Younghun $\mathrm{Kim}^{\dagger}$ \\ Department of Chemical Engineering, Kwangwoon University, 20 Kwangwoon-ro, Nowon-gu, Seoul 01897, Republic of Korea
}

\begin{abstract}
Ammonia, $\mathrm{NH}_{3}$, is a key chemical widely used in chemical industries and a toxic pollutant that impacts human health. Thus, there is a need for the development of effective adsorbents with high uptake capacities to adsorb $\mathrm{NH}_{3}$. An adsorbent with a high surface area and a small pore size is generally preferred in order to have a high capacity for the removal of $\mathrm{NH}_{3}$. The use inorganic nanoporous materials as gas adsorbents has increased substantially and emerged as an alternative to zeolite and activated carbon. Herein, mesoporous alumina (MA) was prepared and used as an $\mathrm{NH}_{3}$ adsorbent. MA showed good pore properties such as a uniform pore size and interlinked pore system, when compared to commercial adsorbents (activated carbon, zeolite, and silica powder). MA has free hydroxyl groups, serving as useful adsorption sites for $\mathrm{NH}_{3}$. In an adsorption isotherm test, MA exhibited 4.7-6.5 times higher uptake capacities for $\mathrm{NH}_{3}$ than commercial adsorbents. Although the larger surface areas of adsorbents are important features of ideal adsorbents, a regular and interlinked adsorbent pore system was found to be a more crucial factor to adsorb $\mathrm{NH}_{3}$.
\end{abstract}

Keywords: Adsorbents, Ammonia, Mesoporous alumina, Nanopore, Toxic gases

\section{Introduction}

Ammonia $\left(\mathrm{NH}_{3}\right)$ is a valuable chemical resource for use in industry as a fertilizer, refrigerant, and to refine petroleum [1]. However, $\mathrm{NH}_{3}$ is also a toxic gas that has a pungent odor and it has potentially harmful effects on the public [2]. When the $\mathrm{NH}_{3}$ content in the atmosphere exceeds $35 \mathrm{ppm}$, it impacts the health of humans and animals [3]. In addition, an aerodynamic study of particulate matter (PM) in the presence of $\mathrm{NH}_{3}$ found that it played a vital role in the formation of the fine fraction of the aerosol $\left(\mathrm{PM}_{2.5}\right)$ [4]. Hence, $\mathrm{NH}_{3}$ adsorption is of great importance for human health.

Ideal adsorbents with high surface areas and small pore sizes are preferred for high capacities to remove contaminants. Research into such porous materials has gradually addressed these applications with respect to $\mathrm{NH}_{3}$ adsorption or filtration [5-7]. The traditional inorganic adsorbents, including activated carbon, alumina, silica gel, and 13X zeolite, have low adsorption capacities in the range from 2.3 to $12.0 \mathrm{~mol} / \mathrm{kg}$ (37 to $192 \mathrm{mg} / \mathrm{g}$ ) [7]. In recent years, the number of available nanoporous materials, such as mesoporous silica (MS) has increased substantially and emerged as a gas adsorbent alternative to zeolite and activated carbon. The highly regular pore structure and internal surface area of ordered MS make these particles attractive substrates that can be tailored for $\mathrm{NH}_{3}$ adsorption [8]. For example, MS particles showed very high uptake capacities and selectivities for $\mathrm{CH}_{4}$ [9], $\mathrm{CO}_{2}$ [10], $\mathrm{H}_{2} \mathrm{~S}$ [11], $\mathrm{NH}_{3}$ [12], and volatile organic vapors [13]. Few studies on the removal of hazardous gases by adsorption using MA are reported, even though MA and MS share similar pore properties and high thermal stabilities, as seen in comparison to reports about MS in the literature [14, 15].

Therefore, herein, MA prepared by a templating method was used as an $\mathrm{NH}_{3}$ adsorbent. In previous studies [16, 17], MA showed a high adsorption capacity for metal ions $\left(\mathrm{Hg}^{2+}, \mathrm{Pb}^{2+}\right.$, and $\left.\mathrm{As}^{3+}\right)$ from the aqueous phase. We found that the surface area provided by different adsorbents did not significantly affect the adsorption capacity, and in fact, the key factor was a uniform pore size and an interlinked pore system. Since those particle properties of MA enhanced the adsorption capacity of the substrate for the removal of metal ions, MA might also be helpful to use as gas-adsorbent. Because zeolite, activated carbon and silica nanoparticles were used as commercial gas adsorbents in re-
This is an Open Access article distributed under the terms of the Creative Commons Attribution Non-Commercial License (http://creativecommons.org/licenses/by-nc/3.0/) which permits unrestricted non-commercial use, distribution, and reproduction in any medium, provided the original work is properly cited.
Received April 10, 2017 Accepted June 6, 2017

${ }^{\dagger}$ Corresponding author

Email: korea1@kw.ac.kr

Tel: $+82-2-940-5768$

Copyright (C) 2017 Korean Society of Environmental Engineers 
al-world applications, we also evaluated these materials for their $\mathrm{NH}_{3}$-adsorption capacities.

\section{Materials and Methods}

\subsection{Materials}

As described in our previous reports [16-18], stearic acid and aluminum sec-butoxide were used as the anionic surfactant, and an aluminum precursor was used to prepare MA. The aluminum precursor and stearic acid were dissolved separately in sec-butyl alcohol, and then the two solutions were mixed. A small amount of water was slowly added dropwise to the mixture, generating a white precipitate. After further stirring for $24 \mathrm{~h}$, the resulting materials were calcined for $3 \mathrm{~h}$ at $500^{\circ} \mathrm{C}$. The molar ratio of this reaction mixture was $1 \mathrm{Al}(\mathrm{sec}-\mathrm{BuO})_{3}: 0.2 \mathrm{C}_{17} \mathrm{H}_{35} \mathrm{COOH}$ : 0.04 $\mathrm{NaOH}: 5$ sec-BuOH: $4 \mathrm{H}_{2} \mathrm{O}$. Zeolite $(\mathrm{Ze},<45 \mu \mathrm{m}$, CAS\#1318-02-1), activated carbon (AC, 100 mesh), and silica (Si, $12 \mathrm{~nm}$ ) were purchased from Sigma-Aldrich (St. Louis, MO, USA) and used without further treatment as commercial adsorbents. The porosities of the adsorbents were analyzed by transmission electron microscopy (TEM, JEM-2010, Jeol, Japan). $\mathrm{N}_{2}$ adsorption/desorption experiments were carried out using a BELSORP-mini volumetric adsorption measurement instrument (BEL, Japan), and pore size distributions were calculated using the Barret-Joyner-Halenda (BJH) pore size and volume analytical model on the desorption branch.

\subsection{Adsorption of $\mathrm{NH}_{3}$}

Helium (99.999\%) and $\mathrm{NH}_{3}$ (99.999\%) were used as carrier and target gas molecules, respectively. As shown in Fig. 1, the experimental setup for measuring the isotherm consisted of a stainless-steel column (18 cm length and $2.54 \mathrm{~cm}$ inner diameter) with $5 \mathrm{~g}$ of packed adsorbent sample, a mass flow controller (max. $5 \mathrm{~L} / \mathrm{min}$ ), a pressure controller (max. $5 \mathrm{bar}$ ), and a continuous gas analyzer (AR8500, Smart Sensor, USA). The gas hourly space velocity was fixed as $28 \mathrm{~min}^{-1}$. The desorption of $\mathrm{NH}_{3}$ adsorbed on MA was carried out at $400^{\circ} \mathrm{C}$ at $5 \mathrm{~L} / \mathrm{min}$ He for $2 \mathrm{~h}$. After regeneration, three recycling tests were carried out at a given pressure. In addition, to define the Gibbs free energy for the adsorption of $\mathrm{NH}_{3}$ on $\mathrm{MA}$, the temperature of the reactor was changed from 25 to $5^{\circ} \mathrm{C}$.
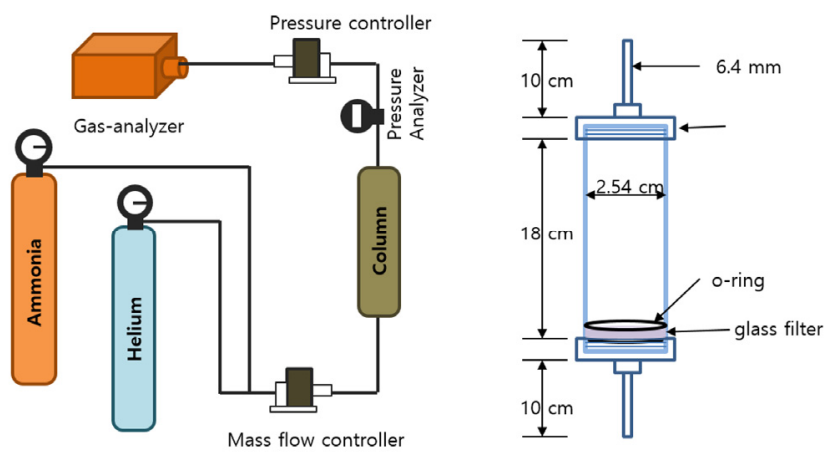

Fig. 1. Experimental system for the adsorption of $\mathrm{NH}_{3}$.

\section{Results and Discussion}

\subsection{Characterizations of Adsorbents}

As shown in Fig. 2 and Fig. 3, MA showed a pore diameter of $3.4 \mathrm{~nm}$ with a narrow and uniform pore size distribution $\left(\mathrm{D}_{\mathrm{FWHM}}\right.$ $\sim 2 \mathrm{~nm}$ ). In the $\mathrm{N}_{2}$ adsorption/desorption isotherm of MA, a typical type of IV isotherm of mesoporous porosity and a hysteresis loop in the range 0.4-0.8 $\mathrm{P} / \mathrm{P}_{\mathrm{o}}$ was observed, showing both the framework and textural porosity of the substrate. The framework porosity was in the range 0.4-0.7 $\mathrm{P} / \mathrm{P}_{\mathrm{o}}$, indicating that the porosity was contained within the uniform channels of the templated framework, whereas the textural porosity in the range $0.8-1 \mathrm{P} / \mathrm{P}_{\mathrm{o}}$ was indicative of the porosity arising from the non-crystalline intra-aggregate voids and spaces formed by interparticle contacts [16]. The TEM images (Fig. 3(a)) of MA showed a sponge-like porous appearance and an interlinked pore system, consistent with the analysis for the $\mathrm{N}_{2}$ adsorption/desorption result of MA. An interconnected pore structure has an advantage of a reduced diffusion limitation and an enhanced molecular accessibility to the inner surface.

However, other adsorbents (AC, Ze, and Si samples) showed irregular and broad pore size distributions, as shown in Fig. 2. The AC sample had a small pore at the inner surface and a large surface area $\left(1,024.2 \mathrm{~m}^{2} / \mathrm{g}\right)$, but both the non-uniform pore structure and very broad pore distribution in the range 1-25 nm did not match with the physical properties of ideal adsorbents. A molecular sieve such as the Ze sample generally has a very small pore (2-10 $\AA$ ), which is too small to be able to adsorb $\mathrm{NH}_{3}$ into the inner surface of $\mathrm{Ze}$. The Si sample consisted of single particle with a size of $12 \mathrm{~nm}$ and aggregates of these particles are depicted in Fig. 2(d). Because the void fraction originated from aggregation between the primary particles, it acted as pores in the $\mathrm{N}_{2}$ adsorption/desorption test. The pore properties of all the adsorbents are listed in Table 1. Therefore, $\mathrm{NH}_{3}$ might be adsorbed on the outer surface of Ze and Si samples, but on both inner and outer surface of MA and AC samples.

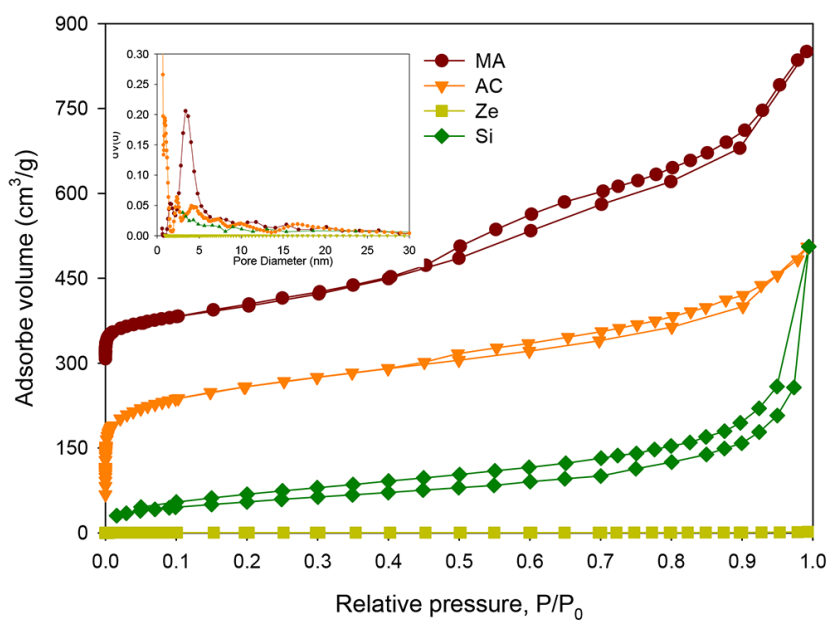

Fig. 2. $\mathrm{N}_{2}$ adsorption/desorption curves for $M A, A C, Z e, S i$ samples. Inset is pore size distribution of 4 adsorbents, calculated by the $\mathrm{BJH}$ model of the desorption branch of the $\mathrm{N}_{2}$ adsorption/desorption test. 


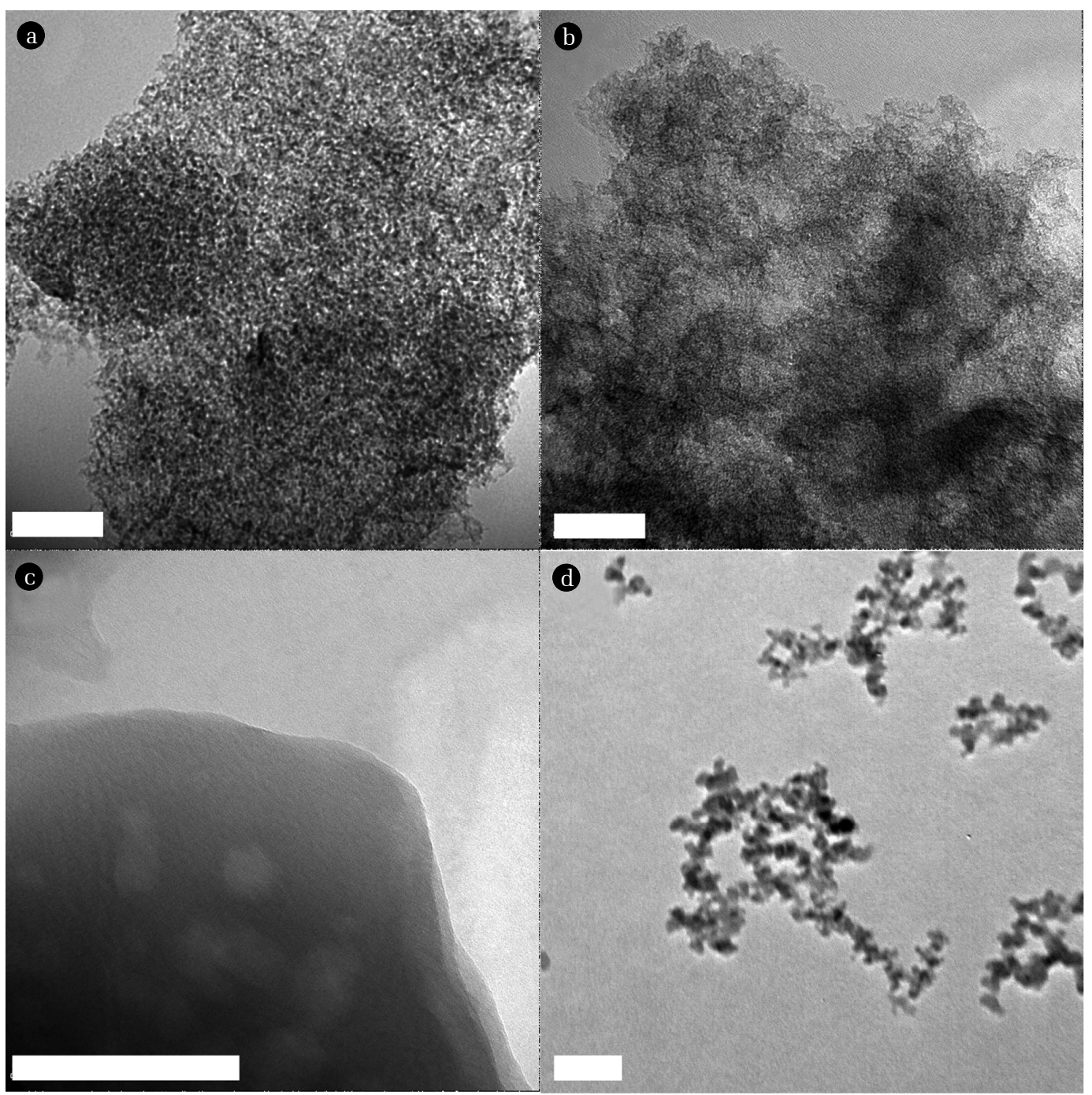

Fig. 3. TEM images of (a) MA, (b) AC, (c) Ze, and (d) Si (1 bar $=50 \mathrm{~nm}$ ).

Table 1. Pore Properties of the Samples

\begin{tabular}{cccc}
\hline Samples & $\begin{array}{c}\text { Surface area } \\
\left(\mathbf{m}^{\mathbf{2}} / \mathbf{g}\right)\end{array}$ & $\begin{array}{c}\text { Pore size } \\
(\mathbf{n m})\end{array}$ & $\begin{array}{c}\text { Pore volume } \\
\left(\mathbf{c m}^{\mathbf{3}} / \mathbf{g}\right)\end{array}$ \\
\hline $\mathrm{MA}$ & 334.2 & 3.39 & 0.759 \\
$\mathrm{AC}$ & $1,024.2$ & 1 to 25 & 0.704 \\
$\mathrm{Ze}$ & 1.9 & $\mathrm{NA}$ & $\mathrm{NA}$ \\
$\mathrm{Si}^{*}$ & 365.8 & $4.92^{*}$ & $1.097^{*}$ \\
\hline
\end{tabular}

* Since silica nanoparticles have not porous nanostructure, its pore size and pore volume in the table mean the void fraction originated from agglomeration or aggregation between primary particles.

\subsection{Adsorption Equilibrium Study}

Applied pressure is the controlling parameter to adjust the gas uptake on adsorbents. When increasing the applied pressure of the $\mathrm{NH}_{3}$ gas, the uptake capacities of adsorbents generally increased to saturation levels at high pressure. As shown in Fig. 4 , the saturation curve for all adsorbents followed a typical
Langmuir isotherm. While the uptake of $\mathrm{NH}_{3}$ gas on MA increased steadily up to 3 bar, AC, Ze, and Si samples showed rapid saturation after 1.5 bar. $\mathrm{NH}_{3}$ molecules were first adsorbed on the outer surface of the adsorbent at a relatively low pressure and then gradually penetrated into the inner surface of the adsorbent to adsorb at a relatively high pressure. Since MA has a uniform pore diameter, $\mathrm{NH}_{3}$ could easily penetrate into the inner surface, leading to an enhancement of the adsorption capacity. Although AC has the largest surface area among the 4 samples, its uptake capacity was smaller than MA and similar to $\mathrm{Ze}$ and $\mathrm{Si}$ samples. It was noted that the irregular pore structure of AC acted as a bottle-neck for the intrusion of $\mathrm{NH}_{3}$ molecules into the inner surface, and thus there was a decrease in the uptake of $\mathrm{NH}_{3}$. Although the Si sample had a similar surface area with MA, induced by the formation of aggregates between single silica nanoparticles, Si also showed a low uptake capacity. These results showed that the surface area of adsorbents did not significantly affect the 


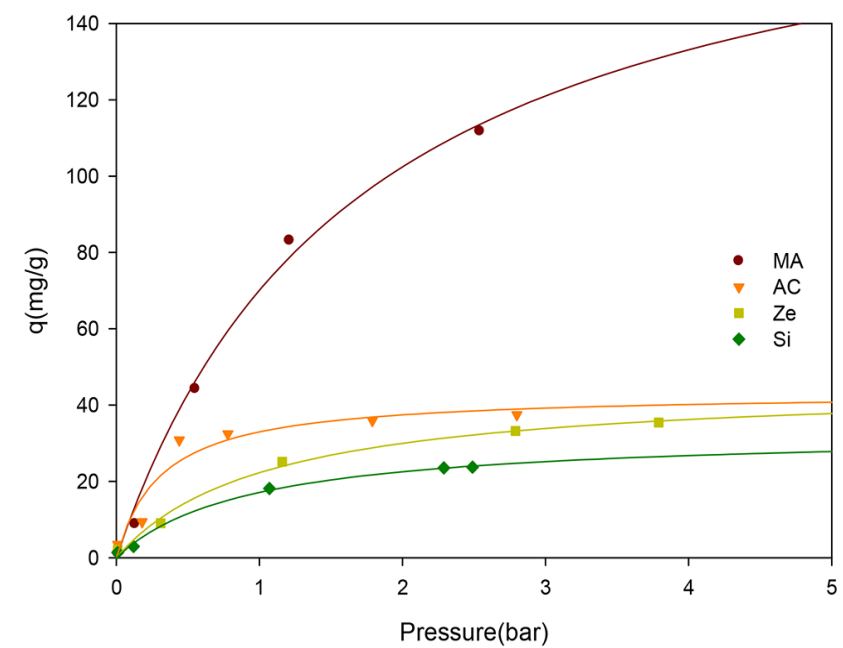

Fig. 4. Isotherms of $\mathrm{NH}_{3}$ on $\mathrm{MA}, \mathrm{AC}, \mathrm{Ze}$, and $\mathrm{Si}$ samples.

Table 2. Parameters of Langmuir Isotherm and Adsorption Density for $\mathrm{NH}_{3}$ on MA, $\mathrm{AC}$, Ze and $\mathrm{Si}$

\begin{tabular}{ccc}
\hline Samples & $\mathbf{Q}_{\mathbf{m}}(\mathbf{m g} / \mathbf{g})$ & $\boldsymbol{\Gamma}_{\max }\left(\mathbf{m g} / \mathbf{m}^{2}\right)$ \\
\hline MA & 214.8 & 0.44 \\
$\mathrm{AC}$ & 45.8 & 0.11 \\
$\mathrm{Ze}$ & 43.3 & 0.10 \\
$\mathrm{Si}$ & 33.0 & 0.08 \\
\hline
\end{tabular}

adsorption capacity. A common feature of the AC and $\mathrm{Si}$ is their irregular pore size distribution. Namely, ill-defined pore structure reduces the adsorption of $\mathrm{NH}_{3}$ to adsorbents. Therefore, the surface area of the adsorbent is likely to be large, but the pore structure (i.e., regular interlinked pore system) is the most important factor for the $\mathrm{NH}_{3}$ adsorption.

The maximum uptake capacities $\left(\mathrm{Q}_{\mathrm{m}}, \mathrm{mg} / \mathrm{g}\right)$ for $\mathrm{NH}_{3}$ was calculated with Langmuir isotherm. As summarized in Table 2, the $\mathrm{Q}_{\mathrm{m}}$ values of the $\mathrm{NH}_{3}$ uptake on MA, AC, Ze, and Si adsorbents was $214.8,45.8,43.3$, and $33.0 \mathrm{mg} / \mathrm{g}$, respectively. MA had 4.7 times high uptake capacity for $\mathrm{NH}_{3}$, compared to AC. It was reported that commercial AC and zeolite have adsorption capacities for $\mathrm{NH}_{3}$ in the range 37-144 mg/g [7]. Therefore, MA used here is referred as a good gas-adsorbent with a very high adsorption capacity for $\mathrm{NH}_{3}$. The adsorption density $\left(\Gamma, \mathrm{mg} / \mathrm{m}^{2}\right)$ of $\mathrm{NH}_{3}$ on the active surface of adsorbents was calculated using the well-known equation, $\mathrm{V} \Delta \mathrm{C} / \mathrm{mS}$, where $\mathrm{S}, \mathrm{m}, \mathrm{V}$, and $\mathrm{C}$ are parameters for the surface area, the amount of adsorbent, volume and adsorbed concentration of $\mathrm{NH}_{3}$, respectively [16]. The maximum adsorption density $\left(\Gamma_{\max }\right)$ was obtained from the adsorption isotherm, and a similar trend with the maximum uptake of $\mathrm{NH}_{3}$ was observed (Table 2).

Because the adsorption of gas is strongly affected by temperature, the Gibbs energy and the uptake capacity for MA adsorbent were evaluated at different temperatures $\left(25,30\right.$, and $\left.50^{\circ} \mathrm{C}\right)$. As shown in Fig. 5, the adsorption curve at high temperature was located below that of the room temperature. The maximum capacities of $\mathrm{NH}_{3}$ at 30 and $50^{\circ} \mathrm{C}$ were 174.5 and $132.6 \mathrm{mg} / \mathrm{g}$, respectively, which were lower than those obtained at $25^{\circ} \mathrm{C}$. With increasing

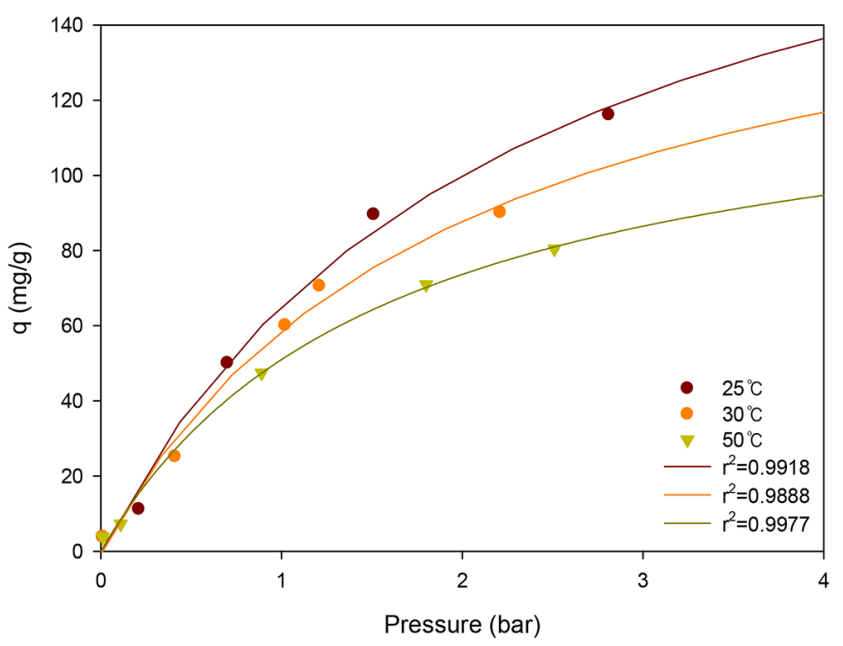

Fig. 5. Isotherms of $\mathrm{NH}_{3}$ on the $\mathrm{MA}$ at a different temperature.

temperature, $-\Delta \mathrm{G}$ was slightly decreased from 12.0 to $11.7 \mathrm{~kJ} / \mathrm{mol}$, decreasing the interaction between $\mathrm{NH}_{3}$ and supports. Therefore, the adsorption system under high temperature poses a negative impact on the adsorption capacity, decreasing the amount of adsorbed gas.

Chemisorption and physisorption of $\mathrm{NH}_{3}$ on oxide material have been studied [12]. In the past literatures, it is reported that $\mathrm{NH}_{3}$ was chemisorbed on silica surface forming the $\mathrm{NH}_{3}-\mathrm{O}-\mathrm{Si}$ [19] or $\mathrm{NH}_{2}-\mathrm{Si}$ [20] with a siloxane bond (Si-O-Si). For physisorption of $\mathrm{NH}_{3}$, the hydroxyl group was the preferred site to bond $\mathrm{NH}_{3}\left(\mathrm{NH}_{3}-\mathrm{OH}-\mathrm{Si}\right)$ [21]. Although the walls of calcined oxide (MS and MA) are made of multiple oxide bridges (Si-O-Si or $\mathrm{Al}-\mathrm{O}-\mathrm{Al}$ bonds), the pore surfaces contain free hydroxyl groups. These free polar groups serve as useful sites for adsorption of polar gas, such as $\mathrm{NH}_{3}$ [22]. In addition, the additional hydroxyl groups formed by hydrothermal conditioning with water increase the acidity of oxide materials, which results in an increase in $\mathrm{NH}_{3}$ capacity [5]. Therefore, similar to the investigation of $\mathrm{NH}_{3}$ adsorption on the silica surface, alumina (MA) has free hydroxyl groups, serving as a useful adsorption site for $\mathrm{NH}_{3}$. As calculated in our previous work [16], the moles of total surface sites per gram of solid were estimated to be $2.5 \mathrm{~mol} / \mathrm{kg}$ for MA, assuming 5 hydroxyls $/ \mathrm{nm}^{2}$ [23]. The maximum capacity of MA was higher than the total moles of hydroxyl sites (as described in isotherm results), and thus, $\mathrm{NH}_{3}$ adsorbed on the inner and outer surface of MA via both physisorption and chemisorption using hydroxyl groups and oxo-bridge.

In field applications of $\mathrm{NH}_{3}$ adsorbents, maintaining the initial uptake capacity after regeneration is also an important factor for ideal adsorbents. After the regeneration, the feasibility of the adsorption-desorption cyclic operation was examined to investigate the reproducibility of MA performance, as shown in Fig. 6. The amount of adsorbed $\mathrm{NH}_{3}$ decreased slightly with repeated use of adsorbent (214.8 to $204.2 \mathrm{mg} / \mathrm{g}$ after 3 times recycling). While $>95 \%$ of the initial uptake capacity of $\mathrm{NH}_{3}$ was maintained after three cycles of operations, notably MA could undergo repeated adsorption-desorption cycles without any loss of activity. 


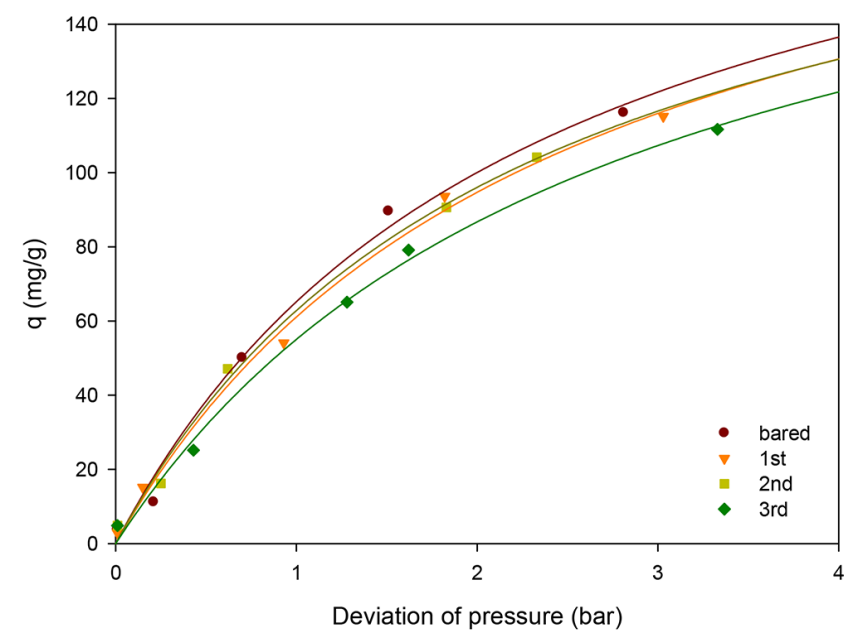

Fig. 6. Isotherms of $\mathrm{NH}_{3}$ on the MA with recycling numbers.

\section{Conclusions}

MA was prepared by a post-hydrolysis method to use as the gas adsorbent for $\mathrm{NH}_{3}$. The MA adsorbent showed pore properties of ideal gas-adsorbents, such as uniform pore size, regular pore size distribution, interlinked sponge-like pore system, and large surface area. The $\mathrm{NH}_{3}$ adsorption performance of MA was compared to commercial gas-adsorbents (activated carbon, zeolite, and silica nanoparticle). This study on the isotherm adsorption represented a typical pressure-dependence as Langmuir isotherm. The maximum uptake capacity of $\mathrm{NH}_{3}$ for MA was 4.7-6.5 times larger than the same parameter for commercial adsorbents. There was no correlation between the uptake capacity and pore properties of adsorbents. Namely, the adsorption performance was not good, even if the surface area was large, as in the case of AC. A uniform pore structure with well-defined channels has been shown to more advantageous over a disordered pore network in terms of access to guest species to the binding sites [23]. Consequently, a regular pore structure (prefer to interlinked pore system) was found to be the most critical factor for the removal of $\mathrm{NH}_{3}$ using MA. In addition, because the adsorption energies of the toxic gases and common adsorbates followed the trend $\mathrm{NH}_{3}>\mathrm{PH}_{3}>\mathrm{H}_{2} \mathrm{~S}>\mathrm{SO}_{2}$ $>$ CO (Barea et al., 2014), it was possible to apply as-prepared MA readily as conventional gas-adsorbents for $\mathrm{H}_{2} \mathrm{~S}, \mathrm{PH}_{3}$, and $\mathrm{NH}_{3}$.

\section{Acknowledgments}

This study was supported by the Research Grant from the Korea Environmental Industry and Technology Institute (2015001960003) and the National Research Foundation of Korea (NRF-2017R1A2B 4001829).

\section{References}

1. Barea E, Montoro C, Navarro JAR. Toxic gas removal: Metal-or- ganic frameworks for the capture and degradation of toxic gases and vapours. Chem. Soc. Rev. 2014;43:5419-5430.

2. Hung CM. Decomposition kinetics of ammonia in the gaseous stream by a nanoscale copper-cerium bimetallic catalyst. $J$. Hazard. Mater. 2008;150:53-61.

3. Chen Y, Li L, Li J, Ouyang K, Yang J. Ammonia capture and flexible transformation of $\mathrm{M}-2(\mathrm{INA})(\mathrm{M}=\mathrm{Cu}, \mathrm{Co}, \mathrm{Ni}, \mathrm{Cd})$ series materials. J. Hazard. Mater. 2016;306:340-347.

4. Behera SN, Sharma M. Transformation of atmospheric ammonia and acid gases into components of $\mathrm{PM}_{2.5}$ : An environmental chamber study. Environ. Sci. Pollut. Res. Int. 2012;19:1187-1197.

5. Furtado AMB, Liu J, Wang Y, LeVan MD. Mesoporous silica-metal organic composite: Synthesis, characterization, and ammonia adsorption. J. Mater. Chem. 2011;21:6698-6706.

6. Johnson BJ, Melde BJ, Peterson GW, Schindler BJ, Jones P. Functionalized organosilicate materials for irritant gas removal. Chem. Eng. Sci. 2012;68:376-382.

7. Helminen J, Helenius J, Paatero E, Turunen I. Adsorption equilibria of ammonia gas on inorganic and organic sorbents at 298.15 K. J. Chem. Eng. Data 2001;46:391-399.

8. Ruckart KN, Zhang Y, Reichert WM, Peterson GW, Glover TG. Sorption of ammonia in mesoporous-silica ionic liquid composites. Ind. Eng. Chem. Res. 2016;55:12191-12204.

9. Chiang WS, Fratini E, Baglioni P, Chen JH, Liu Y. Pore size effect on methane adsorption in mesoporous silica materials studied by small-angle neutron scattering. Langmuir 2016;6:8849-8857.

10. Hanif A, Dasgupta S, Nanoti A. High temperature $\mathrm{CO}_{2}$ adsorption by mesoporous silica supported magnesium aluminum mixed oxide. Chem. Eng. J. 2015;15:703-710.

11. Belmabkhout Y, Weireld GD, Sayari A. Amine-bearing mesoporous silica for $\mathrm{CO}_{2}$ and $\mathrm{H}_{2} \mathrm{~S}$ removal from natural gas and biogas. Langmuir 2009;25:13275-13278.

12. Zamani C, Illa X, Abdollahzadeh-Ghom S, Morante JR, Rodriguez AR. Mesoporous silica: A suitable adsorbent for amines. Nanoscale Res. Lett. 2009;4:1303-1308.

13. Hung CT, Bai H. Adsorption behaviors of organic vapors using mesoporous silica particles made by evaporation induced self-assembly method. Chem. Eng. Sci. 2008;63:1997-2005.

14. Thote JA, Chatti RV, Iyer KS, et al. N-doped mesoporous alumina for adsorption of carbon dioxide. J. Environ. Sci. 2012;24:1979-1984.

15. Chen $\mathrm{C}$, Ahn WS. $\mathrm{CO}_{2}$ capture using mesoporous alumina prepared by a sol-gel process. Chem. Eng. J. 2011;1666:646-651.

16. Kim Y, Kim C, Choi I, Rengaraj S, Yi J. Arsenic removal using mesoprous alumina prepared via a templaing method. Environ. Sci. Technol. 2004;38:924-931.

17. Rengaraj S, Yeon JW, Kim Y, Kim WH. Application of Mg-mesoporous alumina prepared by using magnesium strearate as a template for the removal of nickel: Kinetics, isohterm, and error analysis. Ind. Eng. Chem. Res. 2007;46:2834-2842.

18. Kim Y, Lee B, Yi J. Effect of framework or textural nanoporosity on the bulk morphology of mesoporous aluminas. Korean J. Chem. Eng. 2007;24:679-682.

19. Griffiths DWL, Hallam HE, Thomas WJ. Infrared study of adsorption and oxidation of ammonia on silica-supported platinum and silica. Trans. Faraday Soc. 1968;64:3361-3369. 
20. Peri JB. Infrared study of $\mathrm{OH}$ and $\mathrm{NH}_{3}$ groups on the surface of a dry silica aerogel. J. Phys. Chem. 1966;70:2937-2945.

21. Blomfield GA, Little LH. Chemisorption of ammonia on silica. Can. J. Chem. 1973;51:1771-1781.

22. Barpaga D, LeVan MD. Functionalization of carbon silica com- posites with active metal sites for $\mathrm{NH}_{3}$ and $\mathrm{SO}_{2}$ adsorption. Microporous Mesoporous Mater. 2016;221:197-203.

23. Wang Y, Bryan C, Xu H, Pohl P, Yang Y, Brinker CJ. Interface chemistry of nanostructured materials: Ion adsorption on mesoporous alumina. J. Colloid Interface Sci. 2002;254:23-30. 